\title{
Maltese with genetic susceptibility to poliomyelitis: Many cases of paralysis are related, posing a dilemma for post- eradication of polio
}

\author{
Wyatt HV* \\ Visiting Fellow in Philosophy, University of Leeds, Leeds LS2 9HD, UK
}

\begin{abstract}
This is the first study of genetic susceptibility to paralytic poliomyelitis in a defined population over more than one epidemic. All 1,072 cases of Maltese with poliomyelitis in the islands of Malta from 1909 to 1964, and baptism matched controls, were traced to their great grand-parents or beyond. All marriages were checked for consanguinity. Many cases were closely related with many consanguineous marriages of parents and forebears. At least $54 \%$ of the 958 polios on Malta (excluding Gozo) were related as sibs and first and second cousins in several kinship groups. These family groups of polios show genetic susceptibility to poliomyelitis and pose a dilemma for post-eradication of polio.
\end{abstract}

\section{Introduction}

There have been many studies of genetic susceptibility to polio over the last century, but there was little interest as research was focussed on the search for a vaccine. With the possibility of the eradication of polio and the ending of immunisation, awareness of genetic susceptibility has become important. There is interest in genetic susceptibility to infectious diseases in humans [1-3] and recent research has shown that consanguinity is a risk factor for some infectious diseases [1]. Although many epidemics of poliomyelitis have been examined, none have looked for past cases of paralysis and so few have found genetic susceptibility. Aycock looked at individual cases, but his familial cases were dismissed by mainline researchers [4]. After the fiascos of the 1934 polio vaccines, researchers believed that small doses of virus gave immunity, larger doses produced paralysis and that cases of paralysis excreted more virulent virus. These beliefs were not testable. Moreover, search for genetic susceptibility was ignored.

Malta, with the smaller island of Gozo, with 200,00 to 300,000 people in the late $19^{\text {th }} \mathrm{C}$ and mid- $20^{\text {th }} \mathrm{C}$, is usually described as 'Malta'. All were Roman Catholic and married with church and government records. With the approval and support of the Chief Government Medical Officer in 1982, I found the names of 1,072 Maltese children with poliomyelitis from 1909 to 1964 . With the approval and support of the Director of the Public Registry (a lawyer), the Archbishop of Malta, the Bishop of Gozo and their Kappillans (parish priests) I traced the parents, grand-parents and great grand-parents of these polios, together with baptism matched controls. Polios and controls were allotted to the parishes of their great grand-parents. I have traced more than 3,500 births and 16,000 marriages. This first study of a complete population over many years shows that in many families there were sibs and relatives who suffered paralysis in different epidemics [5,6]. Many of these polios have since died, emigrated, moved or are not traceable through the Electoral Register. Very few Maltese adults were paralysedall had immunity from infections in epidemics when children. Very few babies under six months were paralysed as they received antibodies from their immune mothers.

The records in Malta are based on the boundaries of the church parishes, some of which date from the $16^{\text {th }}$ century. Most parishes surround the church in the middle of the village, but in the years of these records, there were many farmhouses around the villages. However, although living in adjacent parishes, families might be close neighbours. Some of the larger parishes encompassed more than one village, some of which have now formed new parishes eg Sliema, Gzira and Saint Julians have split from Birkirkara. Floriana was split from the town of Valletta which itself has two parishes. I have used parish rather than village except where the latter is more appropriate.

\section{Materials}

After the epidemic of 1942-1943 Professor Seddon, a polio expert from Oxford, was sent to the island and examined all the patients. Some Maltese doctors were trained by him. The Chief Government Medical Officer gave me access to the records from 1926 to 1964 of the Infectious Diseases Hospital and those of the Physiotherapy Department. I traced a control baptised five days before or after each polio. Dispensations, required for degrees of consanguinity, were traced in the church marriage records, as well as the Curias in Floriana and Victoria (Gozo). Consanguinities are shown by Roman numerals (eg II is a marriage between first cousins).

\section{Results}

Many of the polio cases were paralysed from six months to three yr of age and almost all were under five yr. The epidemics started in Malta

Correspondence to: Wyatt HV, Visiting Fellow in Philosophy, University of Leeds, Leeds LS2 9HD, UK, Tel: +44 (0)113 264 6679; E-mail: nurhvw@leeds.ac.uk

Key words: consanguinity, genetic susceptibility, poliomyelitis, Sibs

Received: June 01, 2016; Accepted: June 29, 2016; Published: July 01, 2016 
and spread through the island and, in many years, to Gozo. In several of the epidemics, like those in 1942, 1945 and 1948, the poliovirus came from Egypt and is believed to have infected almost everyone in the two islands so that the only cases of paralysis were the children born since the previous epidemic. In his report, Seddon noted that two cases lived next door to each other [7]. If he had enquired, he did not think it was important to record that they were first cousins.

On the island of Malta (excluding Gozo) there were 968 polio cases between 1909 and 1964, although I found only one case, a priest whose parents were Italian, from the 1919 epidemic. Forty eight were sibs, 115 were first cousins and 355 were second cousins. Thus, 518 were related in one or several kinship groups, $54 \%$ of the total. The great grand-mothers of two polios had very rare and unusual maiden names: examination of their marriages showed that they were sisters, so that the polios were related as third cousins. Marriages of the parents of great grand-parents would be in the parish records where many indexes are poor with the handwriting of the kappillans often impossible to decipher, for example Sammut and Zammit. To search these records would more than double the work, as the Public Records only began in 1863 and were incomplete.

I found 26 polio cases before 1942, so that few would have been likely to have had children with polio although several were related to one or more polios through their grand-parents or great grandparents. One mother with polio had, many years later, a son with polio and was herself related to two nephews among six polios in her village (Figure 1).

Prior to the 1942-1943 epidemic there were five cases in the large village (of which one had the polio son) and in several small parishes nearby There were five pairs of sibs related to cases in these parishes. There was a group with seven polios and one control with a number of consanguinities. One polio's parents were II plus II and two other parents of polios were II/III. The marriages of grand-parents of three polios were III and the marriages of the grand-parents of two other polios were both IV. In one of these families with eight grandchildren, five had consanguineous marriages and there were four polio grandchildren. There were cases in the 1942, 1948, 1950, 1956, 1959 and 1961 epidemics.

Although many villages had several families of polios within the village, there were also cases where polios in more than one village were related. In one family group in two villages, there were two cousins: one was related to a second cousin while the other was related to three. One of the latter was also related to a second cousin (Figure 2).

In one family group with seven polios in three adjacent parishes, there had been many consanguineous marriages including a double

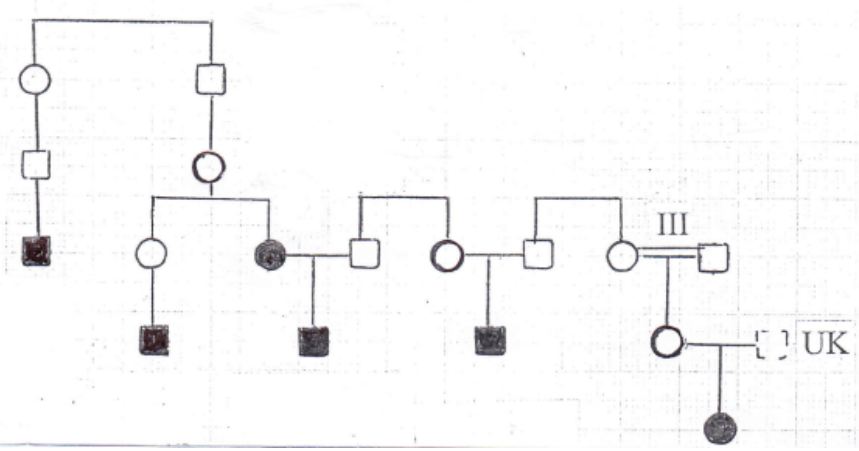

Figure 1. Six polios in one village with a polio mother and, many years later, a polio son.

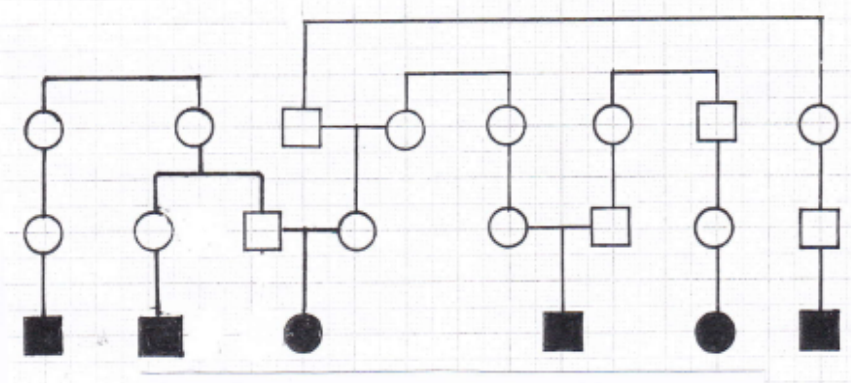

Figure 2. Six polios from two adjacent villages.

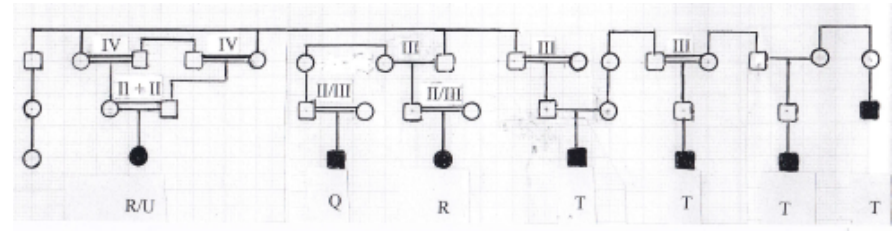

Figure 3. Seven polios from a small village and a large adjacent parish. The circle on the left is a control female from the small village.

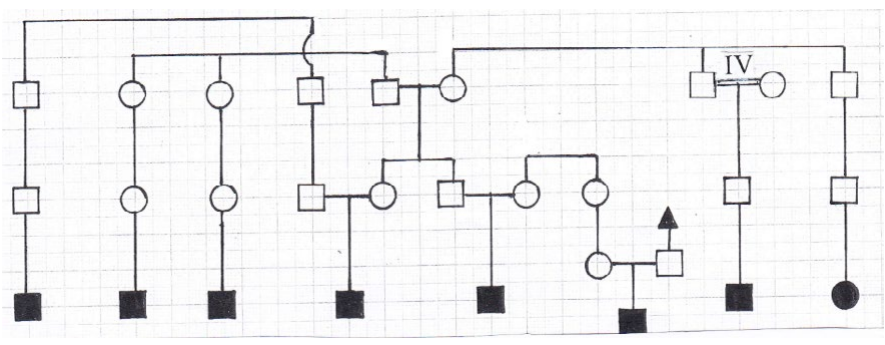

Figure 4. Eight polios from four widely separated villages with one father related to many other polios in his home parish, but conscripted to a new village.

II and two II/III marriages among parents (Figure 3). One family group in four large parishes had nine polios (of which two were sibs, the elder paralysed before the other was born) with 13 links to each other in 1929, 1942, 1950 and 1951. None of the parent or grand-parent marriages were consanguineous.

Another family group with eight polios was dispersed in four parishes with one father conscripted in the army and married to a girl in his new village (Figure 4). This father came from a parish with a very large farming area where many polios were linked in family groupings. Two unusual surnames (including that of the father) were conspicuous with eight polios (including two sibs, the elder paralysed before the other was born) and several consanguineous marriages. Marriages to families in seven other parishes extended the numbers to at least 45 polios in this network. A partial map of this family network has been published [5].

In one large area with several small and large villages, there were many groups of related cases, mostly in different epidemics. In one large village there were three cousins with polio, of whom one had a III/IV grandparent. In the same village, four cousins (one with grandparent IV) were related to a larger group in another area, and through one, to two cousins, through another to another cousin, and through the last to three cousins. In another large village there were a brother and sister, cousins to a girl (grandparent IV) and another two polios. In two large 
villages there were two groups of three cousins, two girls and a boy in one and two girls and a boy in the other.

In another four villages there were six related cases, a mother and her son with three boys, pairs of cousins with a fourth daughter through another cousin (grandparent III). In one large village there were three cousins, two with grandparents III and IV. Seven polios were linked through four second cousins (one grandparent IV) to another three. There were four cases in three villages linked as cousins and second cousins.

One small isolated village had nine polios of which there were two families each with two sibs. Eight of these polios were related to eight others from neighbouring parishes, making a family complex of 16 with several consanguinities (Figure 5). The 16 polios were related with 24 links to each other and six of these polios were linked to two controls in the same family complex. One of these from another parish, case \#826, escaped the 1942 epidemic, but was paralysed in 1950. Case \#242 was not related to others in the parish, but was related through a maternal great grand-parent to case $\# 250$ in another parish: her maternal grand-parents were IV plus IV. There were several related cases in the surrounding parishes although these were some distance away.

\section{Consanguinity among parents and grand-parents of sibs}

Professor Seddon found 6 pairs of sibs among the 396 civilian polio cases [7]. My examination of the records to include cases up to 1964 uncovered many more pairs of sibs - both sibs with polio, others of one polio and one control and those of two control sibs. The proportion of children with paralysis fell with each succeeding year from 1942, no doubt because increasing numbers of children were effectively immunised by circulating wild viruses of lower virulence. Where there were polio and control sibs, the control child would have been a heterozygote and not susceptible until much older [4]. There were many more polio sibs than the others, more with and greater degrees of consanguinity. Consanguinities were common among both polios and controls and often complicated (Table 1) [8]. Some families, particularly in small isolated areas, had many consanguineous relatives, see Figs 3 and 5. There were 110 polios with relatives from Gozo: 15 were under $1 \mathrm{yr}$ and $90 \%$ were under $5 \mathrm{yr}$. There were 4 pairs of sibs. Two villages had very complicated patterns of related polios with many ancesters of consanguinous marriages. One remote village was known for its inbreeding, but the other, much larger, contained a small group with a limited group of ancesters.

\section{Discussion}

Neither time nor place can explain why, when all were exposed to infection, out of about 300,000 people in 1950, a few families suffered multiple children with polio. In dozens of small incidents and large epidemics, separated by location and years, cases occurred in the same families e.g. 23 cases over 30 years in one village. Although genetic susceptibility has been ignored for 100 years and WHO says that only 1 in 200 is paralysed, in dozens of epidemics, one in 50 was paralysed $[9,10]$. In 1948 a virgin soil epidemic affected two out of 53 Inuit children and $26 \%$ of the adults: Sabin interpreted this to be 'an isolated highly inbred population of special genetic susceptibility', but failed to recognise that two \% and $26 \%$ was the Hardy-Weinberg ratio [4]. He did not consider that the heterozygotes would also carry the gene for susceptibility. How could genetic susceptibility be confined only to one Inuit group, but never occur elsewhere? How can strains of different virulence only cause paralysis to the same proportion of cases (up to $2 \%$ in very young children and in hypogammaglobulinaemic children) unless there is an underlying genetic susceptibility?

Although one small village in Gozo has been cited as having extensive intermarrying [11-13], a much larger parish had a greater proportion of polio cases (Table 2). In this parish, the related polio and control cases were part of a tight family group. It is difficult to compare the incidence in different parishes as there were many infant deaths and significant deaths up to five yr: in 1933 in the village of Siggiewi, Malta, the infant mortality was 630 per thousand and deaths up to five yr were 750 per thousand. The infant mortality fell markedly from 1948, due to the use of DDT, which killed the ubiquitous flies. I examined the registers of the Infectious Diseases Hospital from 1926 onwards and there were very few admissions for diseases such as diphtheria, almost all the admissions were for summer diarrhoea, carried no doubt by flies.

As in the more cosmopolitan towns of Valletta/Floriana and Cospicua and Senglea, there were far fewer consanguineous marriages in parish $\mathrm{P}$ and a lower incidence of polio (Table 2).

There were probably differences between villages related to standards of hygiene, overcrowding, consanguinities and wealth which were reflected in infant mortality and possibly polio [14,15]. Because the control children were matched with polios, they are overrepresented compared to controls of all children.

Simply looking at the total number of consanguineous marriages in a parish is not enough: one should look at the relationships over several generations and those closely related in groups. A marriage between cousins may increase the risk of a particular disease in their children, but the accumulation of risks in families due to multiple consanguinities among previous ancestors, may be more important [8].

I have found 39 cases with paralysis prior to the 1942-1943 epidemic and of these, seven were from Gozo. Although the numbers are small, one might have expected only four from Gozo as the population was about one tenth that of Malta. In the years after 1943, Gozo had fewer outbreaks than Malta suggesting that the virus travelled less frequently to Gozo. Nevertheless, the 100 or so cases from Gozo were similar to

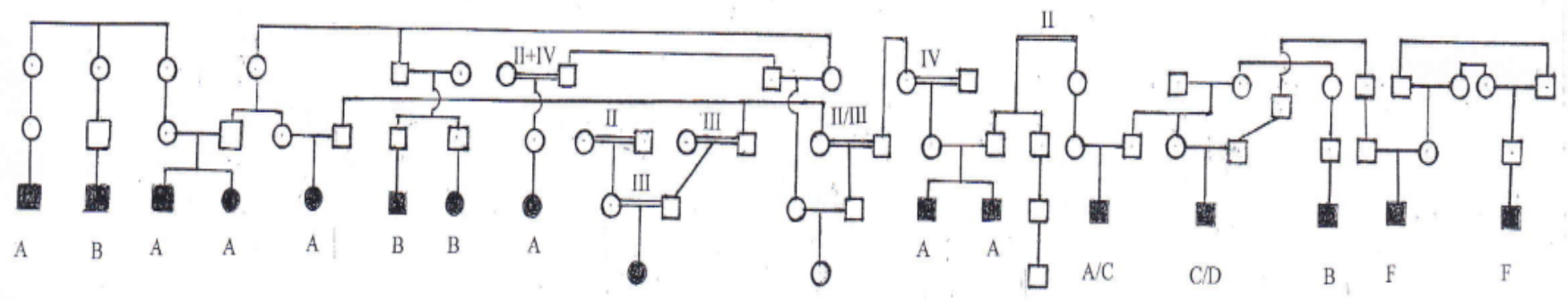

Figure 5. Sixteen polios in a complicated network of families in four parishes, with nine from one small isolated parish. 
Table 1. Consanguinities of related polios and controls in one parish.

\begin{tabular}{|c|c|c|c|}
\hline \multicolumn{4}{|l|}{ Polios } \\
\hline \multirow[b]{2}{*}{$\begin{array}{l}\text { Consanguinities } \\
\text { Numbers }\end{array}$} & Parents & Grand-parents & Great grand-parents \\
\hline & $\begin{array}{l}\text { III } \\
2\end{array}$ & $\begin{array}{l}\text { II II/III III III/IV IV } \\
\begin{array}{llll}1 & 1 & 1 & 2\end{array} 1\end{array}$ & $\begin{array}{l}\text { III III/IV } \\
11\end{array}$ \\
\hline \multicolumn{4}{|c|}{ Controls who had links with polios or other controls. } \\
\hline & Parents & Grand-parents & \\
\hline $\begin{array}{l}\text { Consanguinities } \\
\text { Numbers }\end{array}$ & $\begin{array}{l}\text { II II/III } \\
22\end{array}$ & $\begin{array}{l}\text { II III III/IV IV } \\
3 \# 2 \# 12\end{array}$ & \\
\hline
\end{tabular}

\# in one control there was a double consanguinity of II plus II and, in another, III plus III

Table 2. The incidence of poliomyelitis in selected parishes and a town.

\begin{tabular}{|c|c|c|c|c|c|}
\hline & No. of children & & No. of polio & & $\%$ cases/children \\
\hline & $\begin{array}{c}<4 \text { yr } 1931 \\
\text { census* }\end{array}$ & $<1942$ & $1942-1943$ & $>1945$ & \\
\hline parish 1 & 296 & 3 & 8 & 18 & 9.7 \\
\hline parish 2 & 89 & & 3 & 4 & 7.9 \\
\hline parish 3 & 145 & 1 & 4 & 5 & 6.9 \\
\hline parish 4 & 122 & & 3 & 5 & 6.5 \\
\hline parish 5 & 297 & & 12 & 6 & 6.1 \\
\hline parish 6 & 142 & 2 & 4 & 2 & 5.6 \\
\hline Town 7 & 673 & 1 & 7 & 21 & 4.3 \\
\hline parish 8 & 240 & & & 9 & 3.7 \\
\hline
\end{tabular}

* [14] Because of the war, there was no further census until 1948.

the ratio of the populations of the two islands.

One would expect that in the larger island of Malta, consanguinity and evidence of genetic susceptibility would be less than in Gozo and this is so. Nevertheless, there were still groups of polios in the smaller and more isolated villages. There was a changing pattern of consanguineous marriages in both islands over the years. In Gozo an average of $21 \%$ from 1883 to 1918 , fell to $9 \%$ by 1944 whereas in Malta the peak was about 1910 with $9 \%$ falling to 3\% by 1950 (my calculations from data in the Curias). Although there was one family group in area $\mathrm{D}$ (Figure 4), there were fewer consanguineous marriages among other polios on Malta.

In many epidemics due to importation of poliovirus from Egypt by eg servicemen in 1942 and Maltese soldiers and dockyard workers in 1945 and 1947, with probably everyone infected, the same families suffered children with paralysis. On the smaller island of Gozo, there were 110 polio cases of which $67 \%$ were sibs and first and second cousins [6]. Together with the evidence of many cases of sibs with polio when the younger sib was born after paralysis of the elder, this is very strong support for the genetic susceptibility to polio as predicted by my earlier model $[4,15]$ and supported by Wyatt [4] and Burnet [16]. The many children under two yr would be homozygous children $\mathrm{p}^{+} \mathrm{p}^{+}$ whereas older children would include some of $\mathrm{p}^{+} \mathrm{p}^{-}[4,9]$.

\section{Conclusion}

When poliomyelitis is eradicated with ten years without a case of paralysis, immunisation will cease. After that time, two per cent of children will be at risk without immunity should a virus reappear. But ten years after that, there will be cohorts of young people of whom up to $25 \%$ will be at risk of paralysis. Polio or similar viruses may escape from unsuspected sources in laboratories, may be deliberately manufactured, may mutate from other enteroviruses or may have lain dormant in the environment. Recent disclosure of incidents in the US and Europe has drawn attention to dangers from laboratory and manufacturing sources. It will be prudent to have stocks of vaccine available for an emergency, but the knowledge that so many people might be susceptible to paralysis demands that far larger stocks of vaccine than presently envisaged will be required.

Genetic susceptibility for poliomyelitis has not been considered important since the 1930's, but these familial cases and pairs of sibs with polio at different times, provide ample evidence for susceptibility and the need for realistic planning for the post-eradication age.

1. All the notes, cards, printouts, etc are being deposited with the Melitensis Collection of the University of Malta where they will be available to those with permission from the Medical Ethics Committee.

\section{Acknowledgements}

I am grateful for a Royal Society Travel grant for my visit to Malta in 1985, otherwise this study was funded from my pension. There is no conflict of interest.

\section{References}

1. Lyons EJ, Frodsham AJ, Zhang L, Hill AV, Amos W (2009) Consanguinity and susceptibility to infectious diseases in humans. Biol Lett 5: 574-576. [Crossref]

2. Hill AV (1998) The immunogenetics of human infectious diseases. Annu Rev Immunol 16: 593-617. [Crossref]

3. Chapman SJ, Hill AV (2012) Human genetic susceptibility to infectious disease. Nat Rev Genet 13: 175-188. [Crossref]

4. Wyatt HV (1975) Is poliomyelitis a genetically-determined disease: I: A genetic model Med Hypotheses 1: 35-42. [Crossref]

5. Wyatt HV (1993) Poliomyelitis and infantile paralysis: changes in host and virus. Hist Philos Life Sci 15: 357-396.

6. Wyatt HV (2014) Genetic susceptibility to poliomyelitis in the Maltese island of Gozo. Malta Med J 26: 3-8.

7. Seddon HJ (1943) Epidemic of poliomyelitis in Malta 1942-1943. Public Record Office CO 158/543 XP1880.

8. Wyatt HV (2015b) Consanguinity in the Maltese Islands. Malta Med J 27: 37-42.

9. Wyatt HV (1975) Is poliomyelitis a genetically-determined disease? II. A critical examination of the epidemiological data. Med Hypotheses 1: 23-32. [Crossref]

10. Wyatt HV (2015a) Maltese with genetic susceptibility to poliomyelitis: sibs with paralysis at different times. Malta Med $J$ 27: 29-32.

11. Macelli, T, Inglott, PS, \& Sammut, N. 1972. Gozo-the Human ecosystem on an island Report submitted to UNESCO [University of Malta Melitensis collection MZ 34n.

12. Vassallo, L. 1973. Studies on Maltese consanguinity. Privately printed. Malta Med J 2003; $15: 36-37$.

13. Vella F (1962) The frequency of thalassaemia minor in the Maltese Islands. Acta Haematol 27: 278-288. [Crossref]

14. Anon (1931) Tenth census of the Maltese Islands. Government of Malta.

15. Wyatt HV. 2012. Migration, surnames and marriage in the Maltese island of Gozo around 1900. J Maltese Hist 2: 35-41.

16. Burnet M (1981) Biomedical research: changes and opportunities. Perspect Biol Med 24: 511-524. [Crossref]

Copyright: C2016 Wyatt HV. This is an open-access article distributed under the terms of the Creative Commons Attribution License, which permits unrestricted use, distribution, and reproduction in any medium, provided the original author and source are credited. 